\title{
Expressional divergence of insect GOX genes: from specialist to generalist glucose
}

oxidase

Lihong Yang ${ }^{1,2 \#}$, Xiongya Wang ${ }^{1 \#}$, Sufen $\mathrm{Bai}^{2 *}, \mathrm{Xin}^{2}{ }^{2}$, Shaohua $\mathrm{Gu}^{1}$, Chen-Zhu Wang ${ }^{4}$ and Xianchun $\mathrm{Li}^{1,3^{*}}$

1. State Key Laboratory for Biology of Plant Diseases and Insect Pests, Institute of Plant Protection, Chinese Academy of Agricultural Sciences, Beijing 100193, China

2. College of Plant Protection, Henan Agricultural University, Zhengzhou, Henan 450002, China

3. Department of Entomology and BIO5 Institute, The University of Arizona, Tucson, AZ 85721, USA

4. State Key Laboratory of Integrated Management of Pest Insects and Rodents, Institute of Zoology, the Chinese Academy of Sciences, Beijing 100101, China.

\# These authors contributed equally to this work

*Corresponding Authors: Xianchun Li (1xc@email.arizona.edu, 520-6261749) and Sufen Bai (sfbai68@126.com ) 


\section{Highlights}

- GOX activity/transcripts are upregulated with ingestion and growth in both species.

- Dietary factors differentially regulate GOX transcripts/activity in both species.

- GOX activity, but not GOX transcripts, is always higher in the generalist. 
Graphical Abstract

Helicoverpa armigera

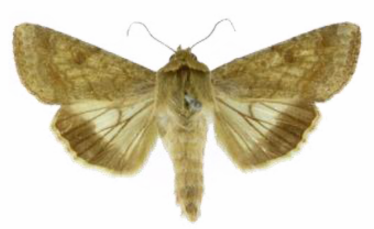

L-ACY-1 gene

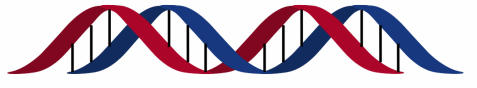

GOX activity

Hostplant range
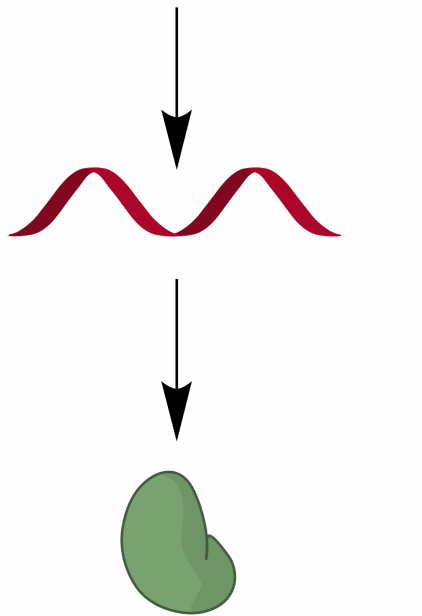

$>1<1=$
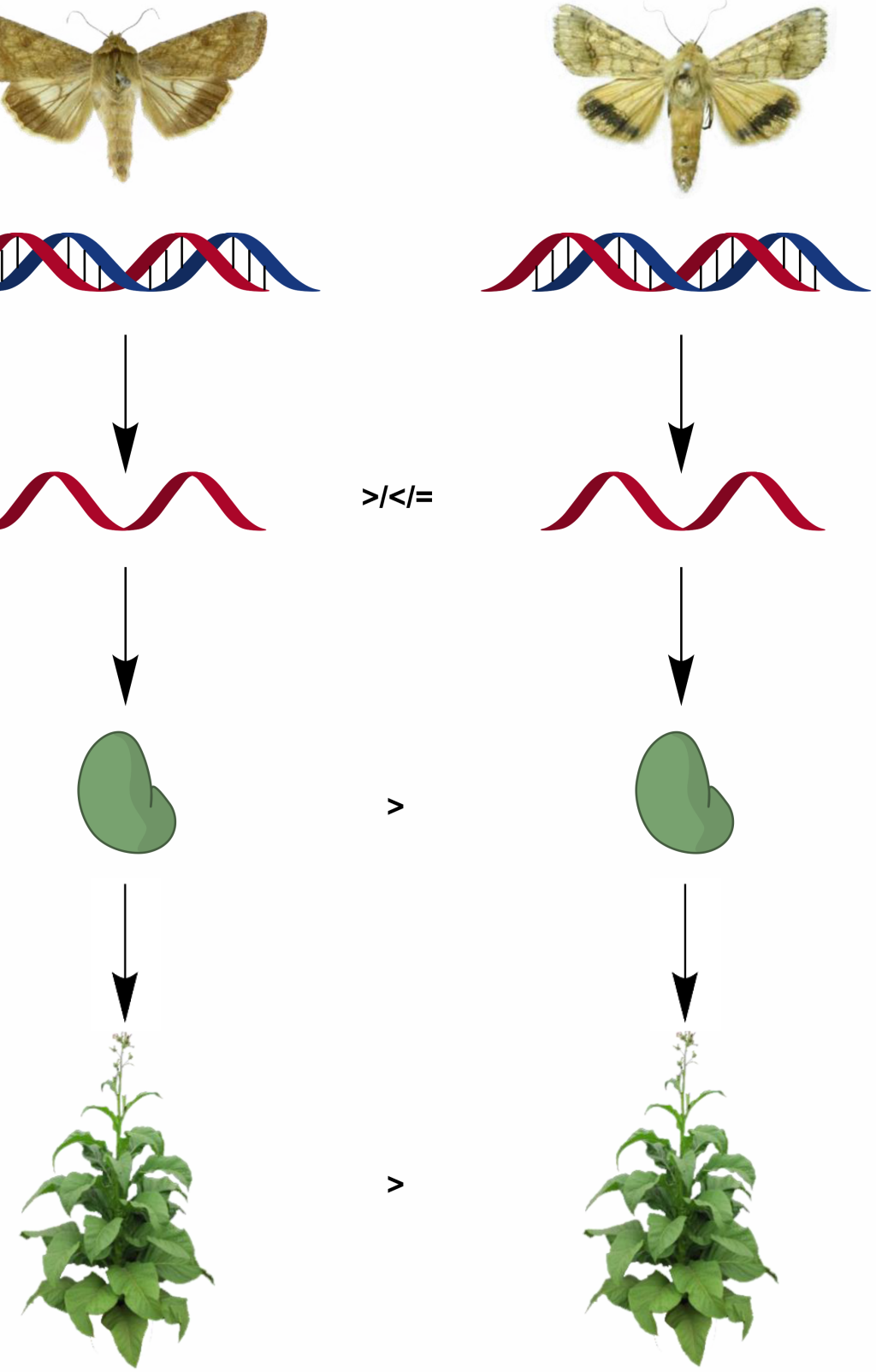
Abstract (238 words): Insect herbivores often secrete glucose oxidase (GOX) onto plants to counteract plant defenses and potential pathogens. Whether generalist herbivores always have significantly higher GOX activities than their specialist counterparts at any comparable stage or conditions and how this is realized remain unknown. To address these two general questions, we subjected larvae of a pair of sister species differed mainly in host range, the generalist Helicoverpa armigera and its specialist counterpart Helicoverpa assulta, to the same sets of stage, protein to digestible carbohydrate $(\mathrm{P}: \mathrm{C})$ ratio, allelochemical or host plant treatments for simultaneous analyses of GOX transcripts and activities in their labial glands. GOX activity and transcripts are upregulated concurrently with food ingestion and body growth, downregulated with stopping ingestion and wandering for pupation in both species. The three tested host plants upregulated GOX transcripts, and to a lesser extent, GOX activity in both species. There were significant differences in both GOX transcripts and activity elicited by allelochemicals, but only in GOX transcripts by P:C ratios in both species. GOX activities were higher in H. armigera than H. assulta in all the comparable treatments, but GOX transcripts were significantly higher either in generalists or in specialists, depending on the developmental stages, host plants, P:C ratio and allelochemicals they encounter. These data indicate that the greater GOX activity in generalist herbivores is not achieved by greater transcription rate, but by greater transcript stability, greater translation rate, better enzyme stability and/or their combination.

Key words: Helicoverpa spp.; GOX expression; Host plant range; Post-transcriptional 
regulation; Translation; RNA stability; P:C ratio; Allelochemicals 


\section{INTRODUCTION}

Specialization and generalization represent two opposite ends of the spectrum for utilization of host plants by herbivorous insects (Li et al., 2004). Specialist herbivores are monophagous species or those feeding on a restricted set of related plant species in the same genus or family, whereas generalists feed on a wide range of plant families (Lankau, 2007; Ali and Agrawal, 2012). Although generalists may have fewer limitations with respect to food availability, they have to cope with the diversity and unpredictability of plant defenses and potential pathogens encountered among potential host plants and environments (Li et al., 2004, 2007; Barthel et al., 2014). Expansion of gene families involved in detoxification and transport of plant defense allelochemicals (Li et al., 2007; Grbić et al., 2011; Clark et al., 2007) and functional versatility of such counterdefense genes (Li et al., 2004) aid generalists in coping with their diverse and unpredictable plant defenses challenge. Evolution of a more efficient immune system, on the other hand, is proposed to protect generalists against a broader range of potential pathogens (Barthel et al., 2014).

While detoxification enzymes and immune response proteins protect insect herbivores from either plant defenses and insect pathogens, respectively, glucose oxidase (GOX), a salivary enzyme secreted onto plants from the labial gland of herbivorous insects (Peiffer and Felton, 2005), has the capacity to beat both plant defenses and insect pathogens (Eichenseer et al., 1999; 2010). GOX has been shown to suppress infectivity of potential pathogen via its catalytic product, hydrogen peroxide (Musser et al., 2005a), a well-known anti-bacterial and anti-fungal agent (Wong et al., 2008). Meanwhile, GOX has also been demonstrated to suppress both direct and 
indirect plant defenses (Musser et al., 2002, 2005b; Zong and Wang, 2004; Bede et al., 2006; Delphia et al., 2006; Weech et al., 2008) by eliciting the SA (salicylic acid) burst and attenuating the JA (jasmonic acid) and ET (ethylene) levels via its catalytic product hydrogen peroxide (Diezel et al., 2009). Moreover, labial gland GOX activity has been found higher in generalists than specialists (Zong and Wang, 2004; Eichenseer et al., 2010), which is consistent with the fact that generalists often encounter a broader range of plant defenses (Li et al., 2007) and potential pathogens. Taken together, GOX appears to be a unique trait that can help generalists to overcome both plant defenses and pathogen challenges.

It is well known that GOX activity in herbivores' labial gland or oral secretion varies significantly, depending on developmental stages (Merkx-Jacques and Bede, 2005; Eichenseer et al., 1999), dietary factors (Hu et al., 2008; Tang et al., 2012; Afshar et al., 2010) and host plants (Peiffer and Felton, 2005; Eichenseer et al., 2010; MerkxJacques and Bede, 2005; Babic et al., 2008). However, it is not clear whether GOX activity is always higher in generalists than specialists at any comparable stages or conditions. If such is the case, does it occur through higher transcription or translation of GOX in generalist? To address these two questions, we subjected H. armigera and H. assulta, a pair of sibling species differed mainly in the host range, to the same sets of stage, host plant, protein to digestible carbohydrate $(\mathrm{P}: \mathrm{C})$ ratio or allelochemical treatments for simultaneous analyses of GOX transcript and activity in their labial glands. We found that GOX activities were higher in the generalist $H$. armigera than the specialist $H$. assulta in all the comparable treatments. However, the ratios of $H$. 
armigera GOX transcripts over H. assulta GOX transcripts ranged from 0.38 to 3.90 and were often at least 2 times smaller than the corresponding activity ratios. These results indicate that GOX activity is always higher because of greater translation efficiency and/or stability of GOX mRNA in H. armigera than H. assulta.

\section{MATERIALS AND METHODS}

\subsection{Insects}

We used one laboratory strain of $H$. armigera and one laboratory strain of $H$. assulta in this study. The two strains were simultaneously established with adults of each species developed from 2100 larvae of H. armigera (about 60\%) or H. assulta (about 40\%) (indistinguishable at larval stage) collected on tobacco plants from Xuchang (Henan, China) in June 2015. The two strains have been maintained on wheat germ-containing artificial diets $[(57$ protein $(\mathrm{P}): 43$ carbohydrate $(\mathrm{C}))$ (Waldbauer et al. 1984 ) at $27 \pm 1{ }^{\circ} \mathrm{C}, 70 \pm 10 \%$ (for adults) or $40 \pm 10 \%$ (for larvae) $\mathrm{RH}$ and a photoperiod of $16 \mathrm{~L}: 8 \mathrm{D}$ since then.

\subsection{Feeding experiments and preparation of labial salivary glands}

Four different feeding experiments were conducted with 3 biological replicates of 15 newly-molted final instar larvae of both species each for all the treatments. In Experiment 1, we individually weighed 315 (3 replicates $\times 15$ larvae per replicate $\times 7$ time points) newly-molted final instar larvae of each species and placed them in cups with control diets (57P:43C ; 1 larva per cup). We then picked 45 larvae from the experiment every $12 \mathrm{~h}$ until $72 \mathrm{~h}$ and individually weighed them. The labial glands of each larva were dissected out on ice under a dissecting microscope, washed with 
sterilized PBS $\left(2.7 \mathrm{mM} \mathrm{KCl}, 1.5 \mathrm{mM} \mathrm{KH}_{2} \mathrm{PO}_{4}, 137 \mathrm{mM} \mathrm{NaCl}, 8.1 \mathrm{mM} \mathrm{Na} \mathrm{HPO}_{4}\right.$ $\times 7 \mathrm{H}_{2} \mathrm{O}$ ) buffer, resulting in 3 biological replicates of 15 pairs of glands each for subsequent analyses of GOX transcripts and activity. We calculated the relative growth rate of each larva by the formula of ( $\log _{e}$ final weight $-\log _{e}$ initial weight $)$ / growth time (Van Emden, 1969).

In Experiment 2, we fed 45 newly-molted final instar larvae of each species with control diets, leaves of 15-25 cm-tall tobacco plants (variety 'Yabuli'), cotton bolls (cut in half; variety 'Shiyuan 321') or fruits of hot pepper (variety 'Xiaoxin 9') collected from the corresponding plants grew in the open field in Langfang experimental station. In Experiment 3, we transferred 45 newly-molted larvae of each species from the control diet (57P:43C) onto control diets or diets with a P:C ratio of 35:65, 50:50, 80:20 or 90:10. For Experiment 4, we transferred 45 newly-molted larvae of each species from the control diet onto control diets or diets supplemented with $0.1 \%(\mathrm{~W} / \mathrm{W})$ of flavone, capsaicin, quercetin, 3-indolylcarbind, nicotin, 2-tridecanone, chlorogenic acid, xanthotoxin, gossypol, coumarin, or rutin. After $48 \mathrm{~h}$, the labial glands of each larva from each treatment of Experiment 2-4 were dissected out on ice under a dissecting microscope, washed with sterilized pure water, pooled into 3 biological replicates of 15 pairs of glands each and stored in $-80{ }^{\circ} \mathrm{C}$ for subsequent analyses of GOX transcripts and activity.

\subsection{Extraction of crude GOX solutions and total RNA from labial salivary glands}

Each replicate of 15 pairs of labial salivary glands were homogenized in liquid nitrogen to fine powers. Half of the resultant powers were transferred to $1.5 \mathrm{ml}$ 
centrifuge tubes containing $70 \mu \mathrm{L}$ PBS buffer, mixed well and centrifuged at 12,000 $\mathrm{g}$ for $15 \mathrm{~min}$ at $4{ }^{\circ} \mathrm{C}$. The supernatants obtained were used as the crude GOX solution for subsequent GOX activity assays. The remaining half of the labial salivary gland powder were used for extraction of total RNA as described in Li et al. (2000). The total RNA samples obtained were treated with RQ1 RNase-free DNase (i.e. DNase I, Promega, USA) and RNase inhibitor (Thermo, USA) for 40 min to remove potential genomic DNA contamination, extracted with phenol/chloroform/isopropanol, evaluated by 260/280 and 260/230 ratios measured using NanoDrop 2000 (NanoDrop, USA), and stored in $-80{ }^{\circ} \mathrm{C}$ for quantitative RT-PCR (qRT-PCR) analysis of GOX transcripts.

\subsection{Glucose oxidase activity assay}

GOX activity was measured spectrophotometrically using an o-dianisidineperoxidase coupled assay (Bergmeyer et al., 1974; Zong \& Wang, 2004). In brief, we set up GOX enzymatic reactions ( $200 \mu \mathrm{L} /$ reaction/well) in individual wells of a $96-$ well microplate (Coring costar 3590, USA) by adding $20 \mu \mathrm{L} 1.7 \mathrm{mM}$ o-dianisidine- $\mathrm{HCl}$ in $0.1 \mathrm{M}$ potassium phosphate $(\mathrm{pH} 7.0), 165 \mu \mathrm{L} 95 \mathrm{mM}$ D-glucose, $5 \mu \mathrm{L} 10 \mathrm{mg} / \mathrm{ml}$ horseradish peroxidase (Sigma), and finally $10 \mu \mathrm{L}$ of ice-cold each crude GOX solution. This reaction contained an excessive amount of D-glucose $(165 \mu \mathrm{L} 95 \mathrm{mM})$, which was much more than needed not only by GOX, but also by glucose dehydrogenases (Celerio-Mancera et al 2011) likely present in the small amount (10 $\mu \mathrm{L})$ of crude GOX solution. Immediately after adding crude GOX solution, we placed the microplate into the microplate chamber (set at $37^{\circ} \mathrm{C}$ ) of a BioTek Synergy 4 microplate reader (BioTek, 
USA), automatically shook it for $5 \mathrm{sec}$, and measured the absorbance (optical density [OD]) values of all the wells at $460 \mathrm{~nm}$ once per $20 \mathrm{sec}$ for a total of $5 \mathrm{~min}$. Protein concentrations of each crude GOX solution were determined using bovine serum albumin as a standard, following the method of Bradford (1976).

\section{5 qRT-PCR analysis of GOX transcripts}

Each total RNA sample $(1.5 \mu \mathrm{g})$ was reverse transcribed into cDNA at $42{ }^{\circ} \mathrm{C}$ for 1 h in a $20 \mu \mathrm{L}$ reaction consisting of $2 \mu \mathrm{L}$ primer Mix (Tiangen, China), $4 \mu \mathrm{L} d N T P, 1 \mu \mathrm{L}$ M-MuLV reverse transcriptase (New England Biolab) and $1 \mu \mathrm{L}$ RNase inhibitor (Thermo, USA). The resultant cDNAs were used as the templates for qRT-PCR analysis of GOX transcripts using Go Taq qPCR Master Mix kit (Promega). qRT-PCR of GOX, ribosomal protein L-32 (RPL-32) and $\beta$-Tubulin (RPL-32 and $\beta$-Tubulin were used as internal reference genes) were conducted individually in a $20 \mu \mathrm{L}$ reaction containing 10 $\mu \mathrm{L}$ Go Taq qPCR Master Mix, $0.4 \mu \mathrm{L}$ CXR Reference Dye, $0.8 \mu \mathrm{L}$ gene-specific primer pairs $(0.4 \mu \mathrm{L}$ each; Table 1$), 1 \mu \mathrm{L}$ cDNA template and $7.8 \mu \mathrm{L}$ nuclease-free water using an ABI 7500 Real-Time PCR System (Applied Biosystems, Foster City, CA). The common cycling conditions optimized for GOX, RPL-32 and $\beta$-Tubulin were consisted of an initial denaturation at $95{ }^{\circ} \mathrm{C}$ for $15 \mathrm{~min}$, followed by 40 cycles of denaturation at $95{ }^{\circ} \mathrm{C}$ for $10 \mathrm{~s}$, annealing at $60{ }^{\circ} \mathrm{C}$ for $20 \mathrm{~s}$ and extension at $72{ }^{\circ} \mathrm{C}$ for $32 \mathrm{~s}$. Melting curve analysis for the three genes was run from $65^{\circ} \mathrm{C}$ to $95^{\circ} \mathrm{C}$ to ensure free of junk products. Amplification efficiency (E) of each gene (Table 1) was determined from the slope of the log template concentration (x-axis) - Ct value (y-axis) line, using the

formula $\mathrm{E}=10^{-1 / \text { slope }}-1$ (Bustin et al., 2009). The normalized expression level of GOX 
for each stage or feeding treatment of each species was calculated with the geometric mean of the expression of the two reference genes using formula below.

Normalized expression level of GOX

$=\frac{(1+E G O X)^{-C t G O X}}{\sqrt{(1+E R P L-32)^{-C t R P L-32} *(1+E \beta-\text { tubulin })^{-C t} \beta-\text { tubulin }}}$ where $\mathrm{E}$ is amplification

efficiency.

\subsection{Statistical Analysis}

Independent t-tests were conducted to test the significance of differences in GOX activity and transcripts for all treatments between the two Helicoverpa species. Tukey HSD tests were performed to test the significance of differences in GOX activity and transcripts among different developmental stage, host plants, diets supplied with different P:C ratio or plant toxins within each species. All of the statistical tests were performed by SPSS version 17.0 software.

\section{Results}

\subsection{Temporal profiles of GOX activity, GOX transcripts and relative growth rate}

We simultaneously measured the time courses of GOX transcripts and activity in larval labial salivary glands and of relative growth rate in the final instar of $H$. armigera and H. assulta (Fig. 1). The larval growth rate exhibited a similar temporal pattern — reached the maximum at $12 \mathrm{~h}$ post molting and then decreased every $12 \mathrm{~h}$ to a negative value at $60(H$. armigera $)$ or $72 \mathrm{~h}(H$. assulta $)$ when larvae ceased feeding and entered the wandering stage for pupation — in the two sibling species (Fig. 1a). The 
difference was that $H$. armigera grew faster than $H$. assulta, as evidenced by significantly higher growth rate at the first two time points (12 and $24 \mathrm{~h}$ post molting) but significantly lower rate at the last three time points $(36,48$, and $60 \mathrm{~h})$.

Parallel to the time course of the relative growth rate in both species, GOX activity was relatively low in newly-molted final instar larvae $(0 \mathrm{~h})$, rapidly increased 3- (H. assulta) or 7-fold (H. armigera) to its maximum at $12 \mathrm{~h}$, then slightly but not significantly decreased from 12 to $48 \mathrm{~h}$, and finally reached its lowest level from 60 to $72 \mathrm{~h}$ when caterpillars of both species were not feeding but preparing for pupation (Fig. 1B). Between-species comparison showed that GOX activity was numerically higher in H. armigera than H. assulta at all the 7 time points assayed (Fig. 1B and Table 2). Such differences in GOX activity were statistically significant at the middle 4 time points $(12,24,36$ and $48 \mathrm{~h})$ when the majority of food ingestion and body growth in this instar took place (Fig. 1B).

Similarly, GOX transcripts in the larval labial salivary glands of the two Helicoverpa species were low in newly-molted $6^{\text {th }}$ instar larvae, quickly elevated to the highest level from 12 to $48 \mathrm{~h}$ (except for $36 \mathrm{~h}$ in $H$. assulta), the major period of food ingestion and growth, and then dropped to a level that was slightly higher than that of newly-molted larvae from 60 to $72 \mathrm{~h}$, the no feeding and wandering stage prior to pupation (Fig. 1C). Between-species comparison showed numerically more GOX transcripts in H. armigera than in H. assulta at all the time points except for $72 \mathrm{~h}$, which reached significant level only at 12 and $36 \mathrm{~h}$. Such cross-species differences were smaller in GOX transcripts than GOX activity, because the H. armigera / H. assulta 
ratios of GOX activity were 1.20 to 2.64 times of the $H$. armigera / H. assulta ratios of GOX transcripts (Fig. 1B, 1C and Table 2).

\subsection{Impacts of host plants on the amounts of GOX transcripts and activity}

To determine if GOX transcripts and activity levels changed similarly in response to feeding on different host plants, we measured the GOX activity and transcripts in the labial salivary glands of the final instar larvae of both species that were fed with artificial diets (control), detached tobacco leaves (common host plants for both species), cotton bolls (cut in half; favored host plant for $H$. armigera but poor for $H$. assulta), or hot pepper fruits (favored host plant for $H$. assulta but poor for $H$. armigera) for $48 \mathrm{~h}$. For H. armigera, the larvae fed with hot pepper fruits had the highest GOX activity, followed by those fed with cotton bolls, artificial diets, and tobacco leaves (Fig. 2A). In terms of GOX transcripts, it was the highest in the larvae fed with hot pepper fruits, followed by those fed with tobacco leaves, cotton bolls and artificial diets (Fig. 2B). Furthermore, GOX transcripts were significantly higher in the larvae fed with hot pepper fruits than those fed with artificial diets, cotton bolls or tobacco leaves, whereas GOX activity was significantly greater in the larvae fed with hot pepper fruits than those fed with tobacco leaves (Fig. 2A and 2B).

For $H$. assulta, larvae fed with cotton bolls had the highest GOX activity and transcripts, followed by those fed with hot pepper fruits, tobacco leaves and artificial diets (Fig. 2A and 2B). While the differences in GOX activity among the four host plant treatments were not significant (Fig. 2A), GOX transcript was significantly higher in the larvae fed with any of the 3 host plants than the larvae fed with artificial diets 
(Fig. 2B).

Comparison of GOX activity between the two sibling species revealed that GOX activity was numerically always higher in $H$. armigera larvae, regardless of host plants or artificial diets they ate (Fig. 2A). By contrast, GOX transcripts were numerically higher in $H$. armigera larvae fed with hot pepper fruits, tobacco leaves or artificial diets, but numerically lower in H. armigera larvae fed with cotton bolls (Fig. 2B). Significant differences in both GOX activity and GOX transcripts were observed between the two species when they were fed with artificial diets, tobacco leaves or hot peeper fruits, but not with cotton bolls. The H. armigera / H. assulta ratio of GOX activity was the highest in larvae fed with hot pepper fruits (8.29), followed by artificial diets (7.85), tobacco leaves (4.60) and cotton (4.10) (Table 2). By contrast, the $H$. armigera / $H$. assulta ratio of GOX transcripts was not always $>1.0$ and ranged more narrowly from 0.95 (cotton bolls) to 2.37 (hot pepper fruits). As a result, the $H$. armigera / H. assulta ratio of GOX activity was 3.21 (tobacco leaves) to 4.32 (cotton bolls) times of the H. armigera / $H$. assulta ratio of GOX transcripts (Table 2).

\subsection{Effects of protein to digestible carbohydrate ratio on the amounts of GOX transcripts and activity}

To determine if protein to digestible carbohydrate $(\mathrm{P}: \mathrm{C})$ ratio variable in their natural host plants differentially regulates GOX transcripts and activity in the two sibling species, we simultaneously assessed GOX transcripts and activity in the labial salivary glands of their final instar larvae fed for $48 \mathrm{~h}$ on diets with a P:C ratio of 35:65, 50:50, 57:43 (control diet for rearing the laboratory colonies of the two species), 80:20, 
or 90:10. Although the descending order of GOX activity in larval labial salivary glands of $H$. armigera was larvae feeding on 35P:65C diets > 50P:50C diets $>90 \mathrm{P}: 10 \mathrm{C}>$ 57P:43C $\approx 80 \mathrm{P}: 20 \mathrm{C}$, no significant differences in GOX activity were detected among H. armigera larvae fed on the five different $\mathrm{P}: \mathrm{C}$ ratio diets (Fig. 3A). GOX transcripts in the labial salivary glands of $H$. armigera larvae, on the other hand, was the highest when feeding on 50P:50C diets, followed by 35P:65C diets or 90P:10C diets, 57P:43C diets, and 80:20C diets (Fig. 3B). Furthermore, GOX transcripts were significantly higher in $H$. armigera larvae fed on 50P:50C diets than those fed on57P:43C and 80:20C diets. In H. assulta, the descending order of GOX activity was larvae feeding on $35 \mathrm{P}: 65 \mathrm{C}$ diets $\approx 50 \mathrm{P}: 50 \mathrm{C}$ diets $>80 \mathrm{P}: 20 \mathrm{C}$ diets $>90 \mathrm{P}: 10 \mathrm{C}$ diets $>57 \mathrm{P}: 43 \mathrm{C}$ diets (Fig. 3A), whereas that of GOX transcripts were larvae feeding on 35P:65C diets > 50P:50C diets $>$ 80P:20C diets $>57 \mathrm{P}: 43 \mathrm{C}$ diets $>90 \mathrm{P}: 10 \mathrm{C}$ diets (Fig. 3B). There were no significant differences in GOX activity among $H$. assulta larvae feeding the 5 distinct P:C ratio diets (Fig. 3A), but GOX transcripts were significantly greater in $H$. assulta larvae feeding on 35P:65C diets than those feeding on the other four P:C ratio diets (Fig. 3B).

Numerically, GOX activity in larval labial salivary glands was always higher in H. armigera larvae than in $H$. assulta, regardless of the P:C ratio of the diets used to feed their final instar larvae (Fig. 3A). By contrast, GOX transcripts were higher in $H$. armigera than $H$. assulta when their larvae fed on 50P:50C, 57P:43C, 80P:20C and 90P:10C diets, but just opposite on 35P:65C diets (Fig. 3B). The descending order of 6 the $H$. armigera / H. assulta ratio of GOX activity was larvae feeding on 90P:10C diets 
(7.44) > 35P:65C diets (7.18) > 57P:43C diets (6.91) > 50P:50C diets (5.54) > 80P:20C diets (4.95) (Table 2). But the order of H. armigera / H. assulta ratio of GOX transcripts were ranked as follows: 90P:10C diets $(2.60)>50 \mathrm{P}: 50 \mathrm{C}$ diets $(2.19) \approx 57 \mathrm{P}: 43 \mathrm{C}$ diets $(2.12)>80 \mathrm{P}: 20 \mathrm{C}$ diets $(1.50)>35 \mathrm{P}: 65 \mathrm{C}$ diets $(0.78)$. The H. armigera / H. assulta ratio of GOX activity was 2.53 (feeding on 50P:50C diets) to 9.21 (feeding on 35P:65 diets) times of the H. armigera / H. assulta ratio of GOX transcripts (Table 2).

\subsection{Induction of GOX transcripts and activity by plant allelochemicals}

To determine whether allelochemicals present in their common (capsaicin, flavone, quercetin, nicotin, rutin, chlorogenic acid, tridecanone) or unique (for $H$. armigera only: indole-3-carbinol, xanthotoxin, gossypol, coumarin) natural hostplants differentially regulate GOX transcripts and activity in $H$. armigera and $H$. assulta, we measured GOX transcripts and activity in the labial salivary glands of their final instar larvae fed on $0.1 \%$ allelochemical-containing diets for $48 \mathrm{~h}$. When compared with allelochemical-free control diets, GOX activity was significantly induced by coumarin (6.04 induction fold), flavone (5.78 fold) and xanthotoxin (3.99 fold), marginally induced by gossypol (2.16 fold) and chlorogenic acid (1.92 fold), numerically induced by nicotin (1.41 fold), indole-3-carbinole (1.20 fold), quercetin (1.16 fold) and 2tridecanone (1.01 fold), and numerically repressed by rutin ( 0.75 fold) and capsaicin (0.58 fold) in H. assulta (Fig. 4A). Partially different with GOX activity, GOX transcripts were significantly induced by flavone (5.54 fold), coumarin (4.39 fold), 2tridecanone (2.61 fold) and xanthotoxin (2.53 fold), marginally induced by chlorogenic acid (1.90 fold), rutin (1.56 fold), quercetin (1.39 fold) and nicotin (1.36 fold), and 
numerically induced by gossypol (1.22 fold), and numerically inhibited by capsaicin (0.76 fold) and indole-3-carbinol (0.75 fold) (Fig. 4B).

The variations in GOX activity and transcripts were markedly narrower in $H$. armigera than $H$. assulta, as evidenced by lack of allelochemical-elicited significant induction or suppression (Fig. 4A and 4B). GOX activity in H. armigera was marginally induced by xanthotoxin (2.50 fold) and gossypol (2.21 fold), numerically induced by nicotine (1.77 fold), capsaicin ( 1.46 fold), flavone (1.41 fold) and coumarin (1.36 fold), marginally repressed by quercetin ( 0.38 fold), chlorogenic acid ( 0.38 fold) and indole-3-carbinol (0.49 fold), and numerically repressed by 2-tridecanone $(0.85$ fold) and rutin (0.96 fold) (Fig. 4A). Partially different with GOX activity, GOX transcripts were marginally upregulated by nicotine ( 1.65 fold) and gossypol (1.53 fold), numerically upregulated by coumarin (1.12 fold) and capsaicin (1.09 fold), marginally downregulated by chlorogenic acid (0.36 fold), numerically downregulated by quercetin ( 0.83 fold), 2-tridecanone (0.82 fold), rutin (0.89 fold) and xanthotoxin (0.94 fold), and not affected by flavone (Fig. 4B).

Between-species comparison uncovered that GOX activity was always higher in H. armigera than in H. assulta, and the H. armigera / H. assulta ratio of GOX activity ranged from 1.55 (chlorogenic acid) to 19.70 (capsaicin) fold (Fig. 4A and Table 2). By contrast, GOX transcripts were higher in $H$. armigera than $H$. assulta when their larvae fed on control diets (H. armigera / H assulta transcript ratio: 2.12 fold) and diets supplemented with capsaicin (3.03 fold), gossypol (2.66 fold), nicotine (2.58 fold), 
quercetin (1.26 fold) or rutin (1.21 fold), but lower on diets supplemented with flavone ( 0.38 fold), chlorogenic acid ( 0.40 fold $)$, coumarin ( 0.54 fold), 2-tridecanone ( 0.67 fold) or xanthotoxin (0.78 fold) (Fig. 4B and Table 2). The H. armigera / H. assulta ratio of GOX activity was 2.03 (quercetin) to 9.85 (2-tridecanone) times of the $H$. armigera / H. assulta ratio of GOX transcripts (Table 2).

\section{Discussion}

GOX activity in salivary glands or saliva of insect herbivores has been shown to positively correlate with their diet breadth (Zong and Wang, 2004; Eichenseer et al., 2010). However, it is not clear whether GOX activity is always higher in generalist herbivores than their specialist counterparts, no matter what developmental stages they are, what host plants they feed on, and what nutritional components (P:C ratio) and allelochemicals they encounter. In this study, we measured the GOX activity and transcripts in the labial glands of the final instar larvae of H. armigera and H. assulta, a pair of closely-related sister species that differ in host range, which were sampled at 7 different time points post molting, fed with organs of different host plants, or diet with different $\mathrm{P}: \mathrm{C}$ ratio or allelochemicals. We showed that GOX activity and transcripts in both species is upregulated concurrently with food ingestion and body growth, downregulated with stopping ingestion and wandering for preparation of pupation in both species (Fig. 1), and undetectable in prepupa when labial salivary glands undergo programmed cell death (data not shown). Given GOX's involvement in protection from plant defense and potential pathogens (Eichenseer et al., 1999; 2010) and coordination of body growth and pupation by hormones, the similar 
temporal profiles of GOX activity and transcripts observed in both species may be regulated proximately by food ingestion, or distantly by hormones, particularly 20hydroxy ecdysone.

We also showed that the three tested host plants upregulated GOX transcripts, and to a lesser extent (not significantly), GOX activity (except for H. armigera larvae fed with tobacco leaves) in both species, relative to the control diets that are rich in nutrients and free of toxic allelochemicals (Fig. 2). In each species, the poor host plant (hot pepper for H. armigera and cotton for H. assulta) had stronger induction than their common and favorite host plants. The specialist $H$. assulta displayed constitutively lower GOX transcripts and activity but greater induction by host plants than the generalist $H$. armigera. These findings support the notion that GOX plays a counterdefensive role against plant defenses. Plant induction of GOX transcripts (significantly or numerically) and activity (numerically only) in the two Helicoverpa species is consistent with the report that Helicoverpa zea larvae feeding on tobacco had the highest amounts of salivary protein and GOX activity per pair of glands (Peiffer and Felton, 2005), but is different with other reports that found higher GOX activity in insects fed on artificial diets than host plants (Merkx-Jacques and Bede, 2005; Hu et al., 2008; Eichenseer et al., 2010). Such discrepancy could be resulted from differences in varieties of plants, plant tissues tested, compositions of the artificial diets, or insects among these studies.

The observed induction effects of host plants on GOX expression, particularly GOX transcripts in the two Helicoverpa species, are probably caused by relatively 
poorer nutrients (e.g. lower P:C ratio) and/or toxic allelochemicals naturally present in their host plants. That we detected significant differences in both GOX transcripts and activity elicited by allelochemicals, but only significant changes in GOX transcripts by P:C ratios in both species (Fig. 3 and 4) implicates that allelochemicals contribute more to the induction effects of hostplants on GOX. Interestingly, GOX transcripts and activity were correlated positively with sucrose content (10C to $65 \mathrm{C})$ while negatively with protein content (90P to 35P) in H. assulta but not in H. armigera (Fig. 3). This suggests that GOX transcripts and activity are regulated largely by carbohydrate content in H. assulta, but by carbohydrate and protein contents in H. armigera. Consistent with our finding, carbohydrates such as sucrose and glucose were found to increase GOX activities in H. armigera (Hu et al., 2008; Tang et al., 2012) and H. zea (Eichenseer et al., 2010). Likewise, carbohydrates and dietary protein were positively correlated with GOX activity in Spodoptera exigua (Babic et al., 2008), with the former affecting GOX's transcription, and the later effecting GOX's translational and/or posttranslational regulation (Afshar et al., 2010).

Our finding of significantly or at least numerically greater GOX activity in the generalist herbivore $H$. armigra than its specialist counterpart $H$. assulta across all the time points of the final instar and all the treatments of host plant, P:C ratio and allelochemical experiments demonstrate that GOX activity is often higher in generalists than their specialist counterparts. Our cross-species comparison of GOX transcripts provide some insights into the aforementioned divergence in GOX activity between generalist and specialist herbivores. In almost all the time points and more 
than half of the treatments of the three feeding experiments, we found significantly (e.g. hot pepper fruit, tobacco leaves, 50P:50C diets, 90P:10C diets, capsaicin, gossypol, nicotin) or numerically (e.g. 80P:20C diets, quercetin, rutin) higher GOX transcripts in $H$. armigera than $H$. assulta (Fig. 1-4 and Table 2, H. armigera / $H$. assulta ratio $>1$ ) as in the case of GOX activity, but the differences were usually at least 2-fold smaller than those for GOX activity (Table 2). The remaining treatments was just the opposite $(H$. armigera / H. assulta ratio $<1)$, displaying significantly (flavone, coumarin, 2-tridecanone) or numerically (e.g. cotton bolls, 35P:65C diets, chlorogenic acid, xanthotoxin) higher GOX transcripts in the specialist H. assulta than the generalist $H$. armigera. These data indicate that the greater GOX activity in generalist herbivores is not achieved by greater transcription rate, but by greater transcript stability (post-transcriptional regulation), greater translation rate, better enzyme stability and/or their combination. Otherwise, reversion of the H. armigera / H. assulta ratio from $<1$ for GOX transcripts to $>1$ for GOX activity and further expansion of the H. armigera / H. assulta ratio would not happen. Further experiments are needed to resolve the specialist/generalist divergence in post-transcriptional, translational and post-translational regulation of GOX gene.

\section{ACKNOWLEDGMENTS}

This work was supported by USDA National Institute of Food and Agriculture (hatch grant ARZT-1360890-H31-164 and multi state grant ARZT-1370400-R31-168), the National Natural Science Foundation of China (grant 31171874 and 31321004) and 
State Key Laboratory for Biology and of Plant Diseases and Insects (grants SKLOF201402 and SKLOF201504). 


\section{LITERATURE CITED}

Afshar, K., Dufresne, P. J., Pan, L., Merkx-Jacques, M., Bede, J. C., 2010. Dietspecific salivary gene expression and glucose oxidase activity in spodoptera exigua, (lepidoptera: noctuidae) larvae. J. Insect Physiol. 56(12), 1798-1806.

Ali, J. G., Agrawal, A. A., 2012. Specialist versus generalist insect herbivores and plant defense. Trends Plant Sci. 17(5), 293-302.

Babic, B., Poisson, A., Darwish, S., Lacasse, J., Merkx-Jacques, M., Despland, E., Bede, J. C., 2008. Influence of dietary nutritional composition on caterpillar salivary enzyme activity. J. Insect Physiol. 54(1), 286-296.

Barthel, A., Kopka, I., Vogel, H., Zipfel, P., Heckel, D. G., Groot, A. T., 2014. Immune defence strategies of generalist and specialist insect herbivores. Proc. R. Soc. London, Ser. B. 281(1788), 20140897.

Bede, J. C., Musser, R. O., Felton, G. W., Korth, K. L., 2006. Caterpillar herbivory and salivary enzymes decrease transcript levels of Medicago truncatula genes encoding early enzymes in terpenoid biosynthesis. Plant Mol. Biol. 60(4), 519531.

Bergmeyer H U, Gawehn K, Grassl M, 1974. Methods of enzymatic analysis, 2nd ed, Volume I . Academic Press, New York, pp. 457-458.

Bradford, M. M., 1976. A rapid and sensitive method for the quantitation of microgram quantities of protein utilizing the principle of protein-dye binding. Anal. Biochem. 72(1-2), 248-254.

Bustin, S. A., Benes, V., Garson, J. A., Hellemans, J., Huggett, J., Kubista, M., ... Vandesompele, J., 2009. The MIQE guidelines: minimum information for 
publication of quantitative real-time PCR experiments. Clin. Chem. 55(4), 611622.

Celorio-Mancera, M.d.1.P., Courtiade, J., Muck A., Heckel, D.G., Musser, R.O., Vogel, H., 2011. Sialome of a generalist lepidopteran herbivore: identification of transcripts and proteins from Helicoverpa armigera labial salivary glands. PLoS ONE 6(10): e26676. doi:10.1371/journal.pone.0026676

Clark, A. G., Eisen, M. B., Smith, D. R., Bergman, C. M., Oliver, B., Markow, T. A., Pollard, D. A., 2007. Evolution of genes and genomes on the Drosophila phylogeny. Nature, 450(7167), 203-218.

Delphia, C. M., Mescher, M. C., Felton, G., Moraes, C. M. D., 2006. The role of insectderived cues in eliciting indirect plant defenses in tobacco, Nicotiana tabacum. Plant Signaling Behav. 1(5), 243-250.

Diezel, C., von Dahl, C. C., Gaquerel, E., Baldwin, I. T. 2009. Different lepidopteran elicitors account for cross-talk in herbivory-induced phytohormone signaling. Plant Physiol., 150(3), 1576-1586.

Eichenseer, H., Mathews, M. C., Bi, J. L., Murphy, J. B., Felton, G. W., 1999. Salivary 9 glucose oxidase: multifunctional roles for Helicoverpa zea? Arch. Insect Biochem. Physiol. 42(1), 99.

Eichenseer, H., Mathews, M. C., Powell, J. S., Felton, G. W., 2010. Survey of a salivary effector in caterpillars: glucose oxidase variation and correlation with host range. J. Chem. Ecol. 36(8), 885-897. 
Grbić, M., Van Leeuwen, T., Clark, R. M., Rombauts, S., Rouzé, P., Grbić, V., ... Hernández-Crespo, P., 2011. The genome of Tetranychus urticae reveals herbivorous pest adaptations. Nature, 479(7374), 487-492.

Hu, Y. H., Leung, D. W., Kang, L., Wang, C. Z., 2008. Diet factors responsible for the change of the glucose oxidase activity in labial salivary glands of Helicoverpa armigera. Arch. Insect Biochem. Physiol. 68(2), 113-121.

Lankau, R. A., 2007. Specialist and generalist herbivores exert opposing selection on a chemical defense. New Phytol. 175(1), 176-184.

Li, X., Baudry, J., Berenbaum, M. R., Schuler, M. A., 2004. Structural and functional divergence of insect CYP6B proteins: from specialist to generalist cytochrome P450. Proc. Natl. Acad. Sci. U. S. A. 101(9), 2939-2944.

Li, X., Berenbaum, M. R., Schuler, M. A., 2000. Molecular cloning and expression of CYP6B8: a xanthotoxin-inducible cytochrome P450 cDNA from Helicoverpa zea. Insect Biochem. Mol. Biol. 30(1), 75-84.

Li, X., Schuler, M. A., Berenbaum, M. R., 2007. Molecular mechanisms of metabolic resistance to synthetic and natural xenobiotics. Annu. Rev. Entomol. 52, 231-253.

Merkx-Jacques, M., Bede, J. C., 2005. Influence of diet on the larval beet armyworm, Spodoptera exigua, glucose oxidase activity. J. Insect Sci. 5(1), 48.

Musser, R. O., Kwon, H. S., Williams, S. A., White, C. J., Romano, M. A., Holt, S. M., ... Felton, G. W., 2005a. Evidence that caterpillar labial saliva suppresses infectivity of potential bacterial pathogens. Arch. Insect Biochem. Physiol. 58(2), $138-144$. 
Musser, R. O., Cipollini, D. F., Hum-Musser, S. M., Williams, S. A., Brown, J. K., Felton, G. W., 2005b. Evidence that the caterpillar salivary enzyme glucose oxidase provides herbivore offense in solanaceous plants. Arch. Insect Biochem. Physiol. 58(2), 128-137.

Musser, R. O., Hum-Musser, S. M., Eichenseer, H., Peiffer, M., Ervin, G., Murphy, J. B., Felton, G. W., 2002. Herbivory: caterpillar saliva beats plant defences. Nature, 416(6881), 599-600.

Peiffer, M., Felton, G. W., 2005. The host plant as a factor in the synthesis and secretion of salivary glucose oxidase in larval Helicoverpa zea. Arch. Insect Biochem. Physiol. 58(2), 106-113.

Tang, Q., Hu, Y., Kang, L., Wang, C. Z., 2012. Characterization of glucose-induced glucose oxidase gene and protein expression in Helicoverpa armigera larvae. Arch. Insect Biochem. Physiol. 79(2), 104-119.

Van Emden, H. V., 1969. Plant resistance to Myzus persicae induced by a plant regulator and measured by aphid relative growth rate. Entomol. Exp. Appl. 12(1), 125-131.

Waldbauer, G. P., Cohen, R. W., Friedman, S., 1984. An improved procedure for laboratory rearing of the corn earworm, Heliothis zea (Lepidoptera: Noctuidae). Great Lakes Entomol. 17(2), 113-118.

Weech, M. H., Chapleau, M., Pan, L., Ide, C., Bede, J. C., 2008. Caterpillar saliva interferes with induced Arabidopsis thaliana defence responses via the systemic acquired resistance pathway. J. Exp. Bot. 59(9), 2437-2448.

Wong, C. M., Wong, K. H., Chen, X. D., 2008. Glucose oxidase: natural occurrence, 
function, properties and industrial applications. Appl. Microbiol. Biotechnol. 78(6), 927-938.

Zong, N., Wang, C. Z., 2004. Induction of nicotine in tobacco by herbivory and its relation to glucose oxidase activity in the labial gland of three noctuid caterpillars. Chin. Sci. Bull. 49(15), 1596-1601. 
Figures Legends

Fig. 1 Temporal profiles of relative growth rate (A), GOX activity (B) and normalized GOX transcripts (C) in the final instar larvae of $\boldsymbol{H}$. armigera and $\boldsymbol{H}$. assulta. The data and error bars represent the means and standard errors of three replicates of 15 larvae (relative growth rate) or 15 pairs of labial salivary glands (GOX activity and transcripts) each. Values sharing the same letter (small case letters for $H$. assulta and capital letters for $H$. armigera) are not significantly different at $\mathrm{P}<0.05$ (Tukey's HSD tests). Significant $(\mathrm{P}<0.05)$ and extremely significant $(\mathrm{P}<0.01)$ differences between the two species at each time point (GOX activity and transcripts) or period (relative growth rate) are indicated by “*” and “**”, respectively (independent t-test).

Fig. 2 Effects of host plants on GOX activity (A) and normalized GOX transcripts (B) in the final instar larvae of $\boldsymbol{H}$. armigera and $\boldsymbol{H}$. assulta. The data and error bars represent the means and standard errors of three replicates of 15 pairs of labial salivary glands each. Values sharing the same letter (small case letters for $H$. assulta and capital letters for $H$. armigera) are not significantly different at $\mathrm{P}<0.05$ (Tukey's HSD tests). Significant $(\mathrm{P}<0.05)$ and extremely significant $(\mathrm{P}<0.01)$ differences between the two species at each time point are indicated by “*” and "***", respectively (independent t-test).

Fig. 3 Effects of protein to carbohydrate ratio (P:C ratio) on GOX activity (A) and normalized GOX transcripts (B) in the final instar larvae of $\boldsymbol{H}$. armigera and H. assulta. The data and error bars represent the means and standard errors of three replicates of 15 pairs of labial salivary glands each. Values sharing the same letter 
(small case letters for H. assulta and capital letters for H. armigera) are not significantly different at $\mathrm{P}<0.05$ (Tukey's HSD tests). Significant $(\mathrm{P}<0.05)$ and extremely significant $(\mathrm{P}<0.01)$ differences between the two species at each time point are indicated by “*” and “**”, respectively (independent t-test).

\section{Fig. 4 Effect of plant allelochemicals toxins on GOX activity (A) and normalized}

GOX transcripts (B) in the final instar larvae of $\boldsymbol{H}$. armigera and $\boldsymbol{H}$. assulta. The data and error bars represent the means and standard errors of three replicates of 15 pairs of labial salivary glands each. Values sharing the same letter (small case letters for $H$. assulta and capital letters for $H$. armigera) are not significantly different at $\mathrm{P}<$ 0.05 (Tukey's HSD tests). Significant $(\mathrm{P}<0.05)$ and extremely significant $(\mathrm{P}<0.01)$ differences between the two species at each time point are indicated by “*” and “**”, respectively (independent t-test). For indole-3-carbinole, we do not have GOX transcript data for H. armigera. 
Table 1. Primer pairs used for $q R T-P C R$ analysis

\begin{tabular}{|c|c|c|c|c|c|c|}
\hline \multirow[t]{2}{*}{ Gene } & \multirow[t]{2}{*}{ Primer sequences $\left(5^{\prime}-3^{\prime}\right)$} & \multirow{2}{*}{$\begin{array}{l}\text { The length } \\
\text { of the } \\
\text { product (bp) }\end{array}$} & \multicolumn{2}{|c|}{$\begin{array}{c}\text { Primer } \\
\text { amplification } \\
\text { efficiency }(\%)\end{array}$} & \multicolumn{2}{|c|}{$\mathrm{R}^{2}$} \\
\hline & & & $\begin{array}{c}H . \\
\text { armigera }\end{array}$ & $\begin{array}{c}H . \\
\text { assulta }\end{array}$ & $\begin{array}{c}H . \\
\text { armigera }\end{array}$ & $\begin{array}{c}H . \\
\text { assulta }\end{array}$ \\
\hline $\begin{array}{l}\text { beta-Tubulin } \\
\quad(\beta-T U B)\end{array}$ & $\begin{array}{l}\text { F: AGCAGTTCACCGCTATG } \\
\text { TTC } \\
\text { R: AGGTCGTTCATGTTGCT } \\
\text { CTC }\end{array}$ & 106 & 99.311 & 103.73 & 0.9999 & 0.9997 \\
\hline $\begin{array}{l}\text { Ribosomal } \\
\text { protein L32 } \\
(R P L-32)\end{array}$ & $\begin{array}{l}\text { F: CATCAATCGGATCGCTA } \\
\text { TG } \\
\text { R: CCATTGGGTAGCATGT } \\
\text { GAC }\end{array}$ & 152 & 99.5858 & 100.71 & 0.9992 & 0.9997 \\
\hline $\begin{array}{l}\text { Glucose } \\
\text { oxidase } \\
(G O X)\end{array}$ & $\begin{array}{l}\text { F: TGACTACTTGCTGGAAC } \\
\text { TT } \\
\text { R: GCCGTTGAAGAAGAAC } \\
\text { TG }\end{array}$ & 127 & 99.4485 & 96.27 & 0.9999 & 0.9995 \\
\hline
\end{tabular}


Table 2. Comparison of $\boldsymbol{H}$. armigera / H. assulta ratios of GOX activity and GOX transcripts

\begin{tabular}{|c|c|c|c|c|}
\hline \multirow[t]{2}{*}{ Experiments } & \multirow{2}{*}{$\begin{array}{c}\text { Observation } \\
\text { time }(\mathrm{h}) \text { or treatments }\end{array}$} & \multicolumn{2}{|c|}{ H. armigera / H. assulta ratio } & \multirow{2}{*}{$\begin{array}{l}\text { Activity ratio / } \\
\text { Transcripts ratio }\end{array}$} \\
\hline & & GOX activity & $G O X$ transcripts & \\
\hline \multirow{7}{*}{ Stage } & 0 & 1.65 & 1.13 & 1.46 \\
\hline & 12 & 3.91 & 2.13 & 1.84 \\
\hline & 24 & 4.02 & 1.52 & 2.64 \\
\hline & 36 & 4.68 & 3.90 & 1.20 \\
\hline & 48 & 3.92 & 1.83 & 2.14 \\
\hline & 60 & 1.71 & 1.30 & 1.31 \\
\hline & 72 & 1.32 & 0.78 & 1.68 \\
\hline \multirow{4}{*}{ Host plants } & $\operatorname{Diet}(\mathrm{CK})$ & 7.85 & 2.12 & 3.70 \\
\hline & Cotton & 4.10 & 0.95 & 4.32 \\
\hline & Tobacco leaves & 4.60 & 1.43 & 3.21 \\
\hline & Hot pepper & 8.29 & 2.37 & 3.50 \\
\hline \multirow{5}{*}{$\mathrm{P}: \mathrm{C}$ ratio } & $35: 65$ & 7.18 & 0.78 & 9.21 \\
\hline & $50: 50$ & 5.54 & 2.19 & 2.53 \\
\hline & $57: 43$ & 6.91 & 2.12 & 3.26 \\
\hline & $80: 20$ & 4.95 & 1.50 & 3.31 \\
\hline & $90: 10$ & 7.44 & 2.60 & 2.86 \\
\hline \multirow{11}{*}{$\begin{array}{l}\text { Allelo- } \\
\text { chemicals }\end{array}$} & Quercetin & 2.56 & 1.26 & 2.03 \\
\hline & Chlorogenic acid & 1.55 & 0.40 & 3.87 \\
\hline & 3-indolylcarbinol & 3.18 & $\mathrm{ND}^{*}$ & ND* \\
\hline & 2-Tridecanone & 6.60 & 0.67 & 9.90 \\
\hline & Rutin & 10.13 & 1.21 & 8.39 \\
\hline & Coumarin & 1.77 & 0.54 & 3.27 \\
\hline & Flavone & 1.91 & 0.38 & 4.97 \\
\hline & Capsaicin & 19.70 & 3.03 & 6.49 \\
\hline & Nicotine & 9.92 & 2.58 & 3.84 \\
\hline & Gossypol & 8.03 & 2.66 & 3.02 \\
\hline & Xanthotoxin & 4.91 & 0.78 & 6.26 \\
\hline
\end{tabular}

$* \mathrm{ND}=$ no data. 
Fig. 1

A

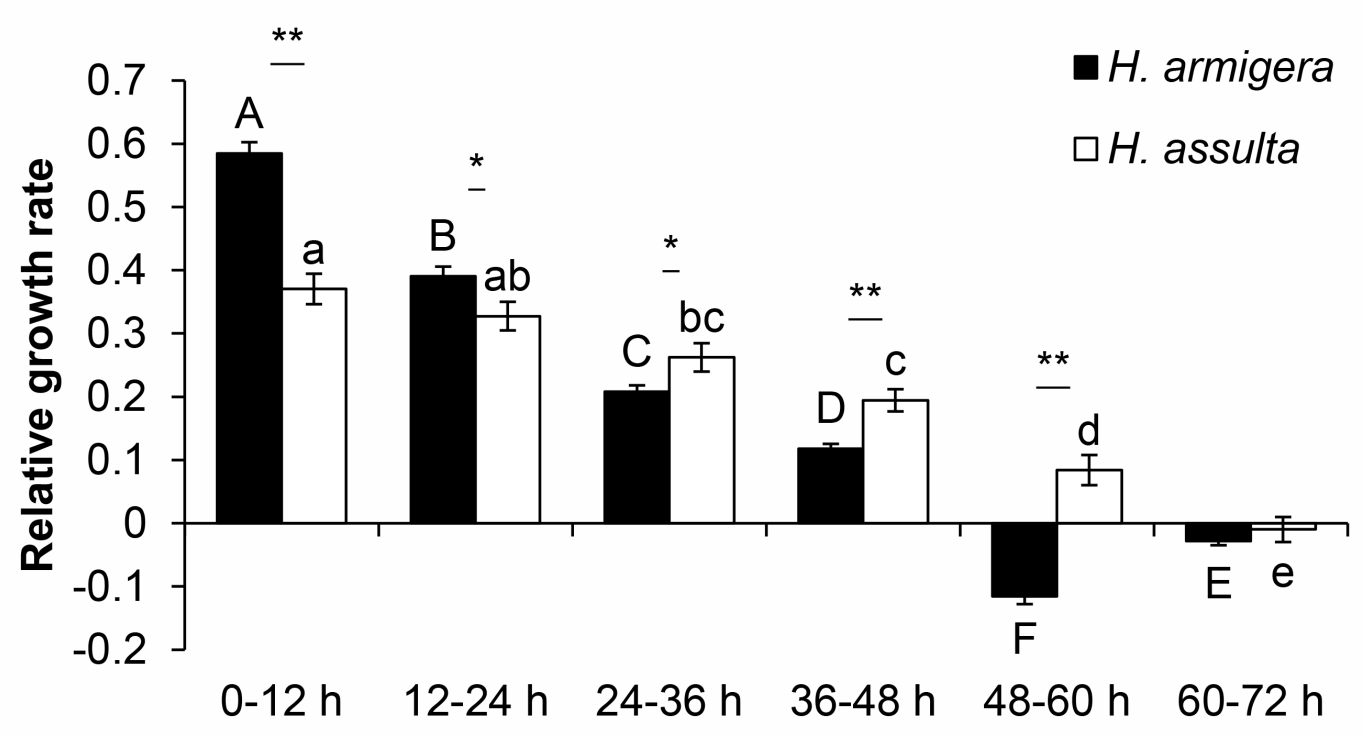

B

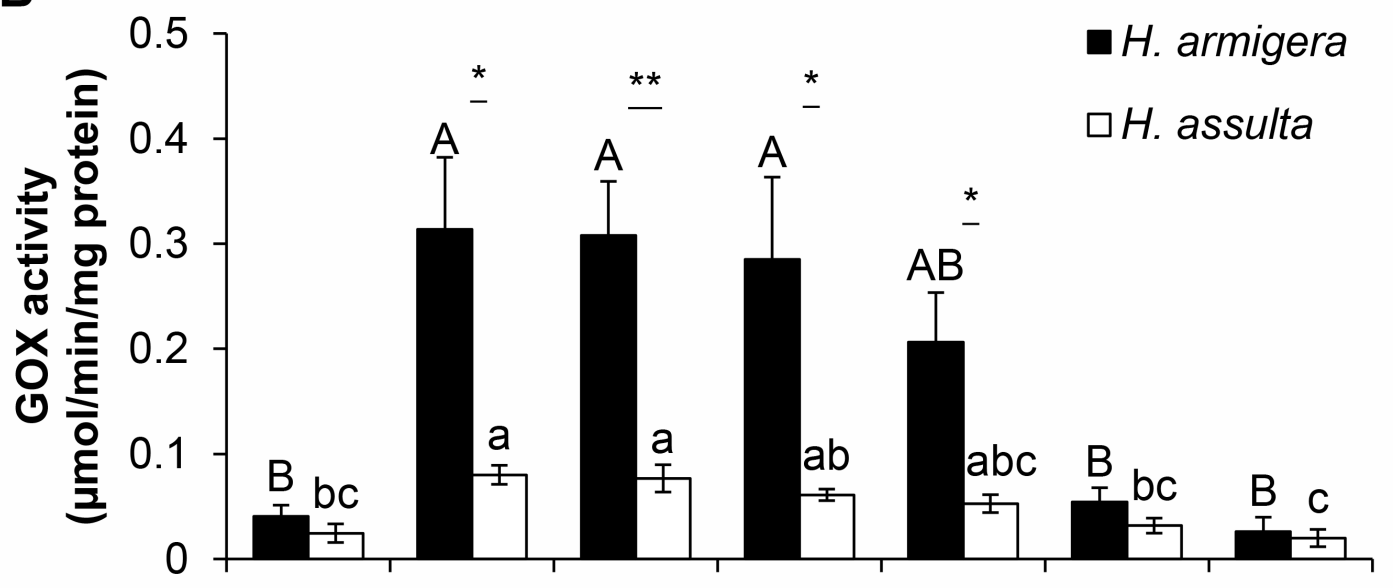

C

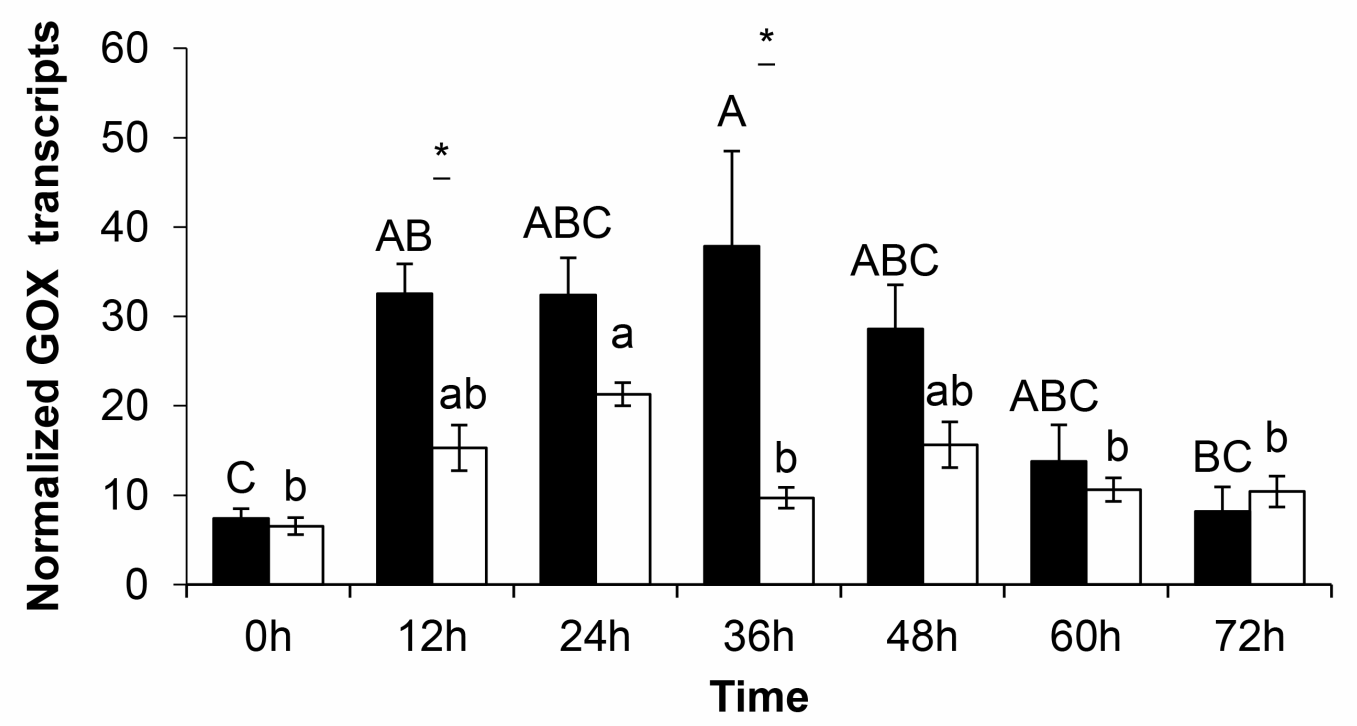


Fig. 2
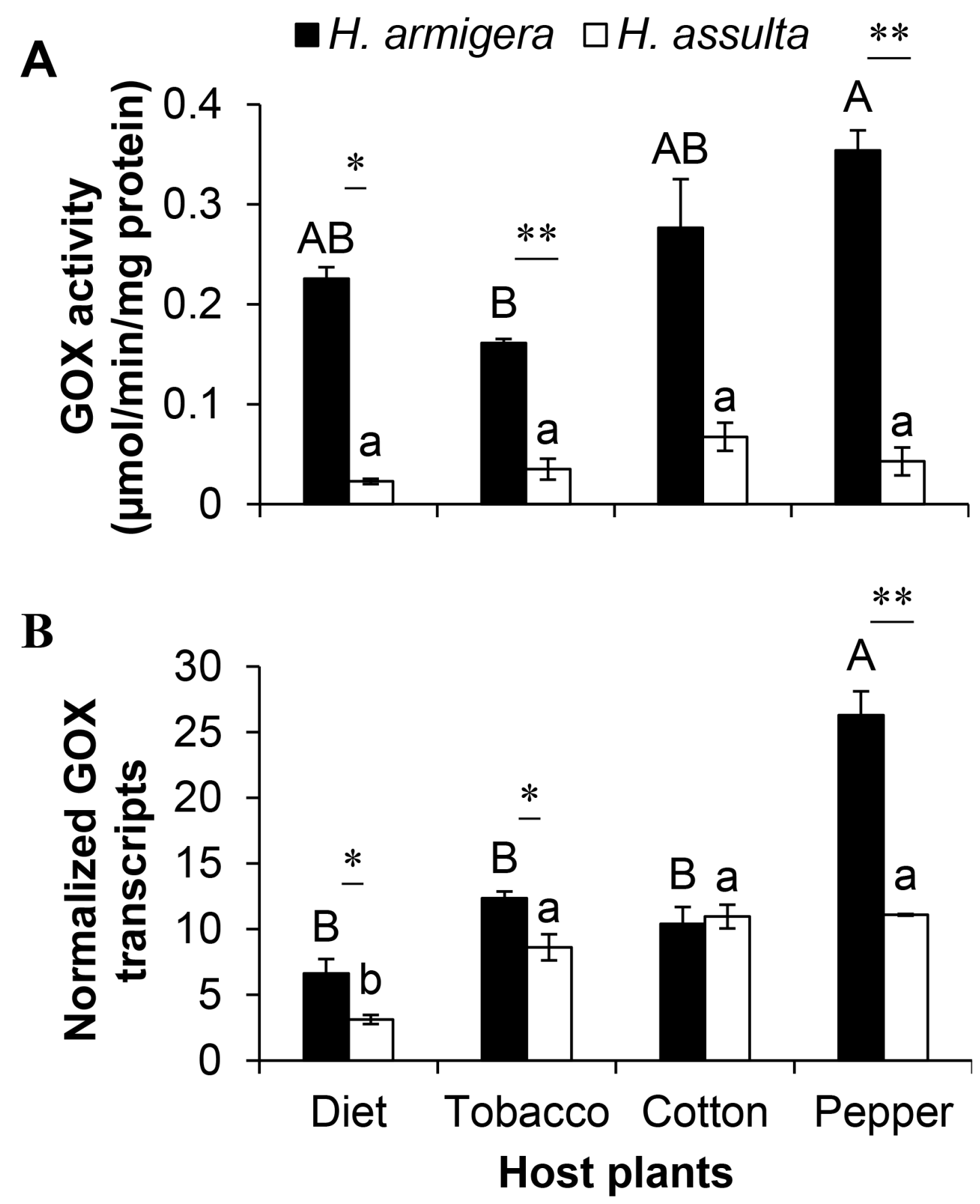
Fig. 3
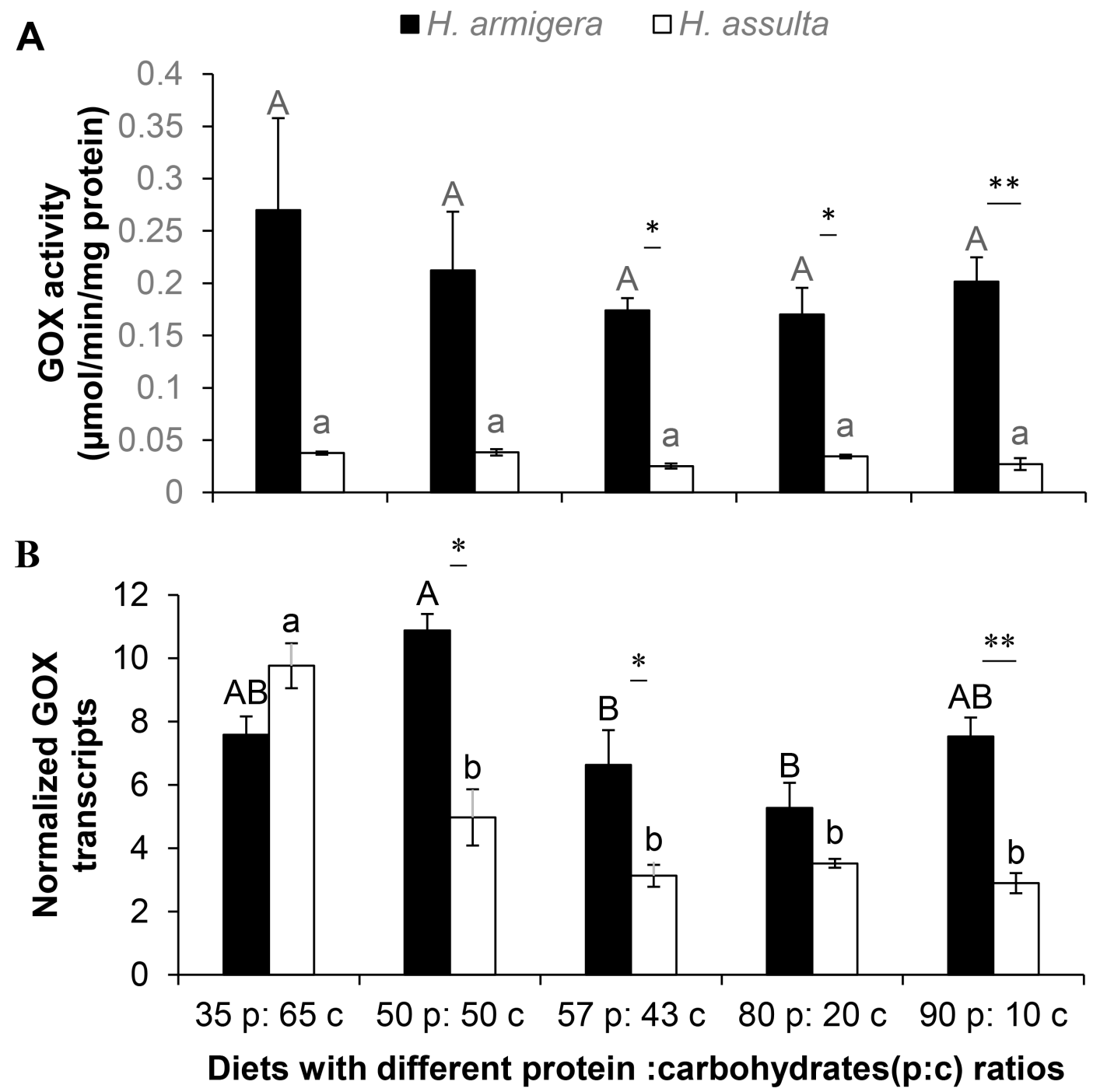
Fig. 4
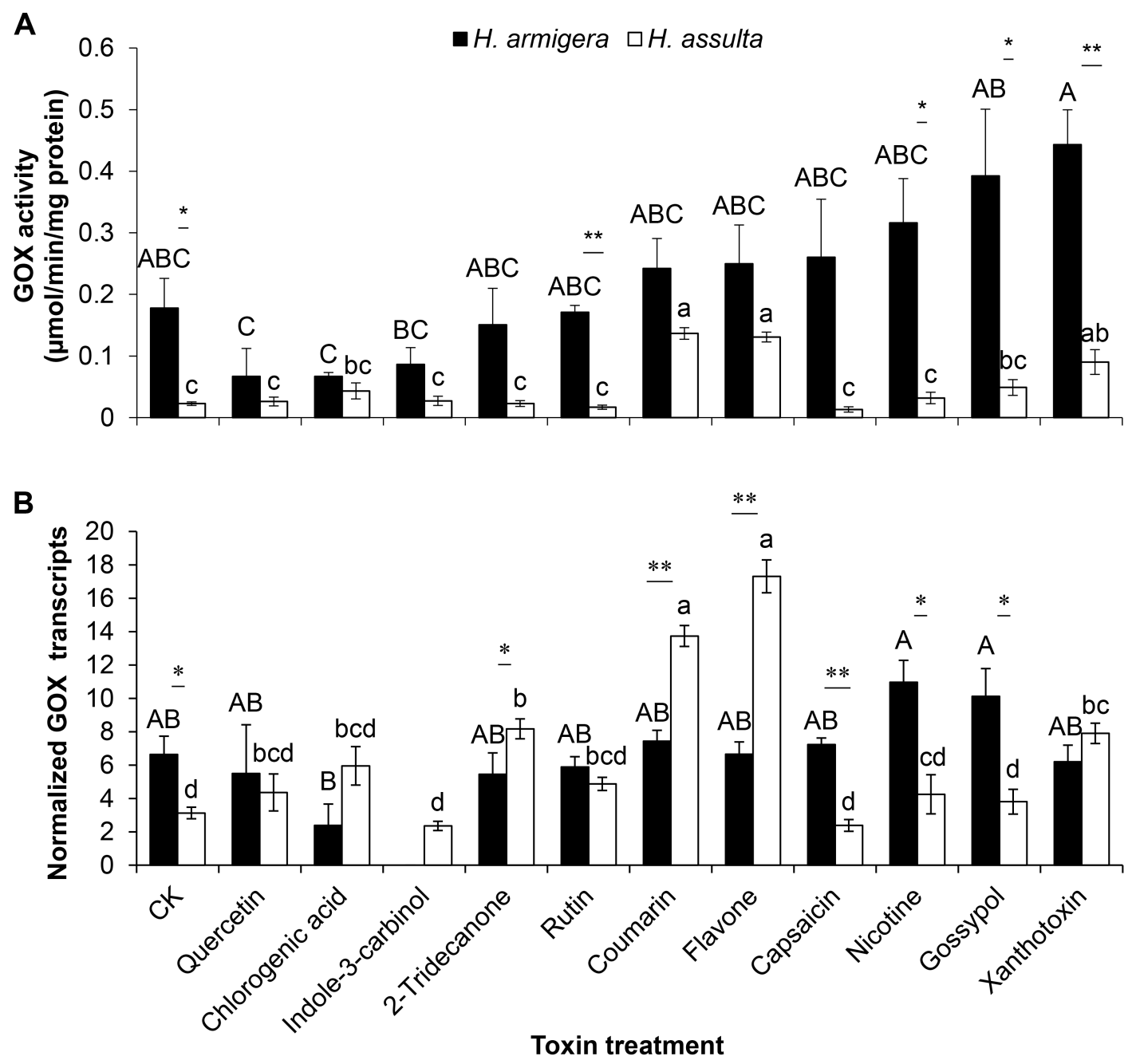